\title{
Plasma B-type natriuretic peptide is a useful tool for assessing coronary heart disease risk in a Japanese general population
}

\begin{abstract}
Takuya Hasegawa ${ }^{1}$, Masanori Asakura ${ }^{1}$, Kazuo Eguchi ${ }^{2}$, Hiroshi Asanuma ${ }^{1}$, Takahiro Ohara ${ }^{1}$, Hideaki Kanzaki ${ }^{1}$, Kazuhiko Hashimura ${ }^{1}$, Hitonobu Tomoike ${ }^{1}$, Jiyoong Kim $^{1}$ and Masafumi Kitakaze ${ }^{1}$

B-type natriuretic peptide (BNP) has been reported to be associated with cardiovascular prognosis in a community-based population. In addition, accumulation of individual cardiovascular risk factors is important in predicting an individual's risk of future cardiovascular disease. However, there have been few reports showing that BNP is a comprehensive marker of the accumulation of cardiovascular risk factors. We studied 1530 community-dwelling subjects without obvious heart diseases or renal dysfunction (mean age $62 \pm 15$ years; 569 men and 961 women) who participated in an annual health checkup in a rural Japanese community. Coronary heart disease (CHD) risk was estimated, and patients were placed into the following three groups based on the Framingham function: low risk, moderate risk and high risk. The prevalence of moderate- and high-risk subjects for CHD rose in both genders with increasing plasma BNP levels. The area under the receiver operating characteristic curve showed a modest ability of plasma BNP levels to detect these subjects $(0.755$ and 0.700 for men and women, respectively). The optimal thresholds for the identification of subjects with moderate- and high-risk disease were BNP concentrations of 12.0 and $22.0 \mathrm{pg} \mathrm{ml}^{-1}$, with sensitivities of $70 \%$ and $66 \%$ and specificities of $71 \%$ and $63 \%$ for men and women, respectively. In conclusion, subjects with high plasma BNP levels were at higher risk for CHD in a population without obvious heart disease or renal dysfunction.
\end{abstract}

Hypertension Research (2015) 38, 74-79; doi:10.1038/hr.2014.123; published online 14 August 2014

Keywords: B-type natriuretic peptide; community-based population; Framingham risk score

\section{INTRODUCTION}

B-type natriuretic peptide (BNP) has been widely used as a diagnostic and prognostic biomarker in heart failure. In the general population, plasma BNP levels may serve as a screening tool to detect left ventricular (LV) systolic dysfunction ${ }^{1-3}$ and other heart diseases, including previous myocardial infarction and hypertensive heart disease. $^{4,5}$ Furthermore, plasma BNP levels can predict the risk of heart failure, ${ }^{6}$ coronary heart disease and stroke ${ }^{7}$ in the general population.

Plasma BNP levels are associated with individual risk factors for coronary heart disease (CHD), such as advancing age, hypertension, diabetes, obesity and dyslipidemia: these factors show different patterns of association with heart disease and have varying impacts on plasma BNP levels. ${ }^{8-11}$ Among these risk factors, advanced age and hypertension are each positively associated with plasma BNP levels, but body mass index (BMI), total cholesterol and triglyceride levels and diabetes are inversely associated with plasma BNP levels, indicating either positive or negative associations between individual coronary risk factors and plasma BNP levels. These risk factors often coexist in a particular patient, and their accumulation increases cardiovascular disease risk. The Framingham Risk Score (FRS) equation is the gold standard for estimating a patient's 10-year risk for CHD by taking into account established risk factors, such as advanced age, hypertension, dyslipidemia, diabetes and smoking. ${ }^{12-14}$ Among the components of the FRS equation, advanced age, hypertension and diabetes are conditions that predispose patients to diastolic heart failure that is strongly associated with high plasma BNP levels. ${ }^{15,16}$ However, calculating the score using a function is not as easy as checking an index derived from blood samples. There have been few studies to determine whether high plasma BNP levels are a surrogate marker of risk factor accumulation. Therefore, we tested the hypothesis that plasma BNP levels predict the risk of CHD estimated by the FRS equation in a rural Japanese population.

\section{METHODS}

Study population

The subjects of our study were selected from a group of participants in the 2005 annual health checkup in Nishi-Arita Town, Saga, Japan. ${ }^{17,18}$ The town had 7249 residents $>20$ years of age. We excluded subjects who underwent their companies' health checkups and those who were unwilling to undergo

${ }^{1}$ Department of Cardiovascular Medicine, National Cerebral and Cardiovascular Center, Suita, Japan and ${ }^{2}$ Department of Cardiology, International University of Health and Welfare Hospital, Nasushiobara, Japan

Correspondence: Dr M Kitakaze, Department of Cardiovascular Medicine, National Cerebral and Cardiovascular Center, 5-7-1, Fujishiro-dai, Suita, Osaka 565-8565, Japan. E-mail: kitakaze@hsp.ncvc.go.jp

Received 6 January 2014; revised 8 June 2014; accepted 15 June 2014; published online 14 August 2014 
this health checkup. Among the 3158 residents invited, 1700 subjects participated in the conventional health checkup. Written informed consent was obtained from all subjects. Individuals who were not willing to participate in the study after obtaining information about it were excluded $(n=162)$. Furthermore, we excluded subjects with a history of myocardial infarction $(n=5)$, heart failure $(n=1)$ or renal insufficiency (serum creatinine $>2.0 \mathrm{mg} \mathrm{dl}^{-1} ; n=2$ ). Following these exclusions, 1530 subjects were enrolled in the study. The study was approved by the Institutional Review Board of our institution. All subjects were ambulatory and provided informed consent to participate in the study.

\section{Baseline clinical evaluation}

All participants were interviewed about their lifestyle, medical history, family history and habits. The subjects were instructed to fast before blood sampling. Standard enzymatic methods were used to determine baseline levels of total cholesterol, high-density lipoprotein (HDL) cholesterol and triglycerides. The Friedwald equation was used to calculate low-density lipoprotein cholesterol levels. Blood pressure was defined as the average of two measurements obtained with subjects in the seated position. Demographic factors were evaluated based on subjects' responses, and anthropometric measurements were obtained using calibrated scales. Hypertension was defined by the following criteria: systolic blood pressure $\geqslant 140 \mathrm{~mm} \mathrm{Hg}$ or diastolic blood pressure $\geqslant 90 \mathrm{~mm} \mathrm{Hg}$ as well as a patient's self-reported history of hypertension or use of antihypertensive medication. Diabetes mellitus was defined by one or more of the following criteria: a patient's self-reported history of diabetes, use of insulin or oral hypoglycemic agents or a fasting glucose $\geqslant 126 \mathrm{mg} \mathrm{dl}^{-1}$. High triglyceride levels were defined as serum triglyceride levels $\geqslant 150 \mathrm{mg} \mathrm{dl}^{-1}$ or ongoing medical treatment for high triglyceride levels. Low HDL cholesterol levels were defined as serum HDL cholesterol levels $\geqslant 40 \mathrm{mg} \mathrm{dl}^{-1}$ for men or $\geqslant 50 \mathrm{mg} \mathrm{dl}^{-1}$ for women or ongoing medical treatment for low HDL cholesterol. Dyslipidemia was defined by the criteria used for either high triglyceride or low HDL cholesterol levels. Metabolic syndrome was defined by following the criteria of the National Cholesterol Education Program (NCEP) in Adult Treatment Panel (ATP) $\mathrm{III}^{13}$ and was diagnosed in patients with $\geqslant 3$ of the following criteria: (1) waist circumference $\geqslant 90 \mathrm{~cm}$ in women or $\geqslant 85 \mathrm{~cm}$ in men, (2) HDL cholesterol $<40 \mathrm{mg} \mathrm{dl}^{-1}$, (3) serum triglycerides $\geqslant 150 \mathrm{mg} \mathrm{dl}^{-1}$, (4) known hypertensive medication use or blood pressure $\geqslant 130 / 85 \mathrm{~mm} \mathrm{Hg}$ and (5) fasting glucose $\geqslant 110 \mathrm{mg} \mathrm{dl}^{-1}$. The cutoff values for waist circumference were modified with values used in Japanese populations. ${ }^{19}$ Estimated glomerular filtration rate was calculated using the equation from the Modification of Diet in Renal Disease Study with coefficients modified for Japanese patients. ${ }^{20}$ BMI was calculated as weight $(\mathrm{kg})$ divided by height $(\mathrm{m})$ squared. Current smoking was defined as having a habit of smoking at the time of the health checkup. Plasma BNP levels were assayed using the chemiluminescent enzyme immunoassay (Shionogi, Tokyo, Japan).

\section{Assessment of 10-year risk for CHD}

The 10-year risk for CHD was determined using the FRS equation, as described in a previous study. ${ }^{13}$ Briefly, the data for age (5-year intervals), plasma total cholesterol and HDL cholesterol levels, systolic blood pressure and cigarette smoking status were taken into account to estimate the 10-year risk for CHD in each gender. Subjects were assigned to the following three groups based on their calculated 10 -year risk: low risk ( 10 -year risk $\geqslant 10 \%)$, moderate risk (10-year risk of $10-20 \%)$ and high risk (10-year risk $>20 \%)$. Subjects with diabetes were assigned to the high-risk group regardless of their 10-year risk for $\mathrm{CHD}$.

\section{Statistical analyses}

Plasma BNP levels were considered categorical and continuous variables after logarithmic transformation. To assess whether a gradient of CHD risk was present across BNP levels, we performed analyses using the following three categories based on tertiles of plasma BNP levels: low tertile, middle tertile and high tertile. Owing to sex-based differences in the distributions of plasma BNP levels, ${ }^{9}$ we established separate cutoff points for men and women and divided subjects evenly into the three categories. One-way analysis of variance was performed to compare continuous variables among the risk subgroups stratified based on plasma BNP levels. The $\chi^{2}$ tests were performed to compare proportional values among the three groups. The differences in the prevalence of the severity of Framingham risk among the three groups based on plasma BNP levels were examined by the $\chi^{2}$ test and logistic regression analysis. In the logistic analysis, odds ratios of the middle-tertile and hightertile BNP groups for moderate-risk and high-risk subjects for CHD were estimated using the low-tertile BNP group as a reference group. Sex-specific receiver operating characteristic (ROC) curves were used to examine the performance characteristics of plasma BNP levels. Areas under the curve and a $95 \%$ confidence interval (CI) of each ROC curve were calculated to provide a measure of the accuracy and ability of plasma BNP levels to detect moderaterisk and high-risk subjects. The ability of BNP to detect subjects with moderate and high risk was evaluated using ROC curves within gender-specific strata. The optimal discriminatory value was identified as the BNP value that had a combined sensitivity and specificity at the smallest distance to $100 \%$ for both men and women. Statistical significance was determined at the $\alpha=0.05$ level using two-sided tests. All analyses were performed using SPSS version 11.0 (SPSS, Chicago, IL, USA).

\section{RESULTS}

\section{Population characteristics}

The overall population characteristics are shown in Table 1. The mean age of the subjects (569 men and 961 women) was $62 \pm 15$ years. The 25th percentile, median and 75th percentile plasma BNP levels in the overall population were 9.1, 17.8 and $33.5 \mathrm{pg} \mathrm{ml}^{-1}$, respectively. The median level in women $\left(18.5 \mathrm{pg} \mathrm{m}^{-1}\right)$ was higher than the median level in men $\left(15.7 \mathrm{pg} \mathrm{ml}^{-1}\right)$. Systemic hypertension and diabetes mellitus were observed in $42 \%$ and $7 \%$ of the subjects, respectively.

\section{Association between plasma BNP levels and each risk factor by gender}

Table 2 shows the comparisons of the population characteristics according to plasma BNP levels. For both genders, positive associations of log-transformed BNP levels were shown with age, indices on hypertension (systolic blood pressure, pulse pressure and the presence of hypertension) and estimated glomerular filtration rate. For men, but not for women, inverse associations of log-transformed BNP values were shown with BMI and indices on dyslipidemia (total cholesterol, low-density lipoprotein cholesterol and triglycerides). The indices on diabetes (fasting glucose level and the presence of diabetes) were not associated with plasma BNP levels in the present study.

\section{Association between plasma BNP levels and Framingham risk} Figure 1 shows the distribution of Framingham risk scores according to plasma BNP levels. The prevalence of low-risk subjects was higher in women than in men in all the BNP subgroups (58\%, 31\% and $9 \%$ for men; $91 \%, 84 \%$ and $67 \%$ for women; low-tertile, middle-tertile and high-tertile $\mathrm{BNP}$, respectively, $P<0.001)$. The prevalence of moderate-risk and high-risk subjects for CHD rose with increasing plasma BNP levels in both genders $(42 \%, 69 \%$ and $91 \%$ for men; $9 \%$, $16 \%$ and $33 \%$ for women; low-tertile, middle-tertile and high-tertile BNP levels, respectively, $P<0.001)$. In men, the odds ratios for the middle-tertile BNP group and the high-tertile BNP group, compared with the low-tertile BNP group (as a reference), were 2.72 (95\% CI $1.76-4.20)$ and 8.73 (95\% CI 4.97-15.33), respectively. In women, the odds ratios for the middle-tertile BNP group and the high-tertile BNP group, compared with the low-tertile BNP group, were 1.98 (95\% CI 1.22-3.24) and 5.26 (95\% CI 3.35-8.26), respectively.

Figure 2 indicates the area under the ROC curve as the ability of plasma BNP levels to detect moderate-risk and high-risk subjects. Plasma BNP levels had a modest ability to detect moderate-risk and 
Table 1 Characteristics of subjects

\begin{tabular}{|c|c|c|c|c|}
\hline & Overall $(n=1530)$ & Men $(\mathrm{n}=569)$ & Women $(n=961)$ & P-value \\
\hline BMI $\left(\mathrm{kg} \mathrm{m}^{-2}\right)$ & $22.3 \pm 3.1$ & $22.5 \pm 2.8$ & $22.3 \pm 3.2$ & 0.215 \\
\hline Systolic blood pressure $(\mathrm{mm} \mathrm{Hg})$ & $129 \pm 21$ & $132 \pm 18$ & $127 \pm 21$ & $<0.001$ \\
\hline Diastolic blood pressure $(\mathrm{mm} \mathrm{Hg})$ & $77 \pm 11$ & $79 \pm 11$ & $75 \pm 11$ & $<0.001$ \\
\hline Pulse pressure $(\mathrm{mm} \mathrm{Hg})$ & $52 \pm 14$ & $53 \pm 13$ & $51 \pm 15$ & 0.052 \\
\hline LDL cholesterol (mg dl-1) & $119 \pm 29$ & $110 \pm 28$ & $124 \pm 28$ & $<0.001$ \\
\hline Triglycerides $\left(\mathrm{mg} \mathrm{dl}^{-1}\right)$ & $102 \pm 64$ & $114 \pm 80$ & $94 \pm 52$ & $<0.001$ \\
\hline Fasting glucose $(\mathrm{mgdl}-1)$ & $87 \pm 22$ & $90 \pm 28$ & $85 \pm 17$ & 0.001 \\
\hline Serum creatinine $\left(\mathrm{mg} \mathrm{dl}^{-1}\right)$ & $0.9 \pm 0.2$ & $1.0 \pm 0.2$ & $0.8 \pm 0.1$ & $<0.001$ \\
\hline Estimated GFR $\left(\mathrm{ml} \mathrm{min}^{-1}\right.$ per $\left.1.73 \mathrm{~m}^{2}\right)$ BNP & $59 \pm 11$ & $60 \pm 11$ & $59 \pm 12$ & 0.039 \\
\hline Median (25th-75th percentile) (pg ml-1) & $17.8(9.1-33.5)$ & $15.7(7.3-33.9)$ & $18.5(10.6-33.4)$ & \\
\hline Low HDL cholesterol (number (\%)) & $456(30)$ & 109 (19) & $347(36)$ & $<0.001$ \\
\hline Current smoking (number (\%)) & $212(14)$ & $179(32)$ & $33(3)$ & $<0.001$ \\
\hline Metabolic syndrome (number (\%)) & 296 (19) & $127(22)$ & $169(18)$ & 0.023 \\
\hline
\end{tabular}

Abbreviations: BMI, body mass index; BNP, B-type natriuretic peptide; GFR, glomerular filtration rate; HDL, high-density lipoprotein; LDL, low-density lipoprotein.

Values are expressed as number of cases $(\%)$ or mean \pm s.d.

Table 2 Comparison of the population characteristics according to plasma BNP levels

\begin{tabular}{|c|c|c|c|c|c|c|c|c|}
\hline & \multicolumn{4}{|c|}{ Men } & \multicolumn{4}{|c|}{ Women } \\
\hline & $\begin{array}{l}\text { Low tertile } \\
(\mathrm{n}=190)\end{array}$ & $\begin{array}{l}\text { Middle tertile } \\
\qquad(\mathrm{n}=190)\end{array}$ & $\begin{array}{l}\text { High tertile } \\
(\mathrm{n}=189)\end{array}$ & P-value & $\begin{array}{l}\text { Low tertile } \\
(\mathrm{n}=321)\end{array}$ & $\begin{array}{l}\text { Middle tertile } \\
\qquad(\mathrm{n}=320)\end{array}$ & $\begin{array}{l}\text { High tertile } \\
(\mathrm{n}=320)\end{array}$ & P-value \\
\hline BNP levels (pg ml-1) & $\leqslant 9.1$ & $9.3-25.0$ & $25.1 \leqslant$ & & $\leqslant 13.0$ & $13.1-27.1$ & $27.3 \leqslant$ & \\
\hline Age (years) & $54 \pm 15$ & $64 \pm 12$ & $73 \pm 9$ & $<0.001$ & $53 \pm 15$ & $61 \pm 14$ & $70 \pm 10$ & $<0.001$ \\
\hline $\mathrm{BMI}\left(\mathrm{kg} \mathrm{m}^{-2}\right)$ & $23.0 \pm 2.8$ & $22.5 \pm 2.7$ & $21.9 \pm 2.8$ & $<0.001$ & $22.4 \pm 3.0$ & $22.3 \pm 3.3$ & $22.1 \pm 3.3$ & 0.580 \\
\hline Waist circumference $(\mathrm{cm})$ & $84.0 \pm 8.1$ & $83.3 \pm 8.0$ & $82.4 \pm 8.2$ & 0.171 & $82.4 \pm 8.7$ & $83.3 \pm 9.8$ & $83.9 \pm 9.9$ & 0.106 \\
\hline Systolic blood pressure (mm Hg) & $129 \pm 16$ & $130 \pm 19$ & $139 \pm 19$ & $<0.001$ & $119 \pm 19$ & $127 \pm 21$ & $134 \pm 22$ & $<0.001$ \\
\hline Diastolic blood pressure (mm Hg) & $79 \pm 11$ & $80 \pm 12$ & $81 \pm 11$ & 0.310 & $74 \pm 11$ & $76 \pm 11$ & $77 \pm 10$ & 0.013 \\
\hline Pulse pressure (mm Hg) & $49 \pm 12$ & $51 \pm 11$ & $58 \pm 14$ & $<0.001$ & $45 \pm 12$ & $51 \pm 14$ & $57 \pm 16$ & $<0.001$ \\
\hline Total cholesterol (mg dl ${ }^{-1}$ ) & $192 \pm 30$ & $186 \pm 31$ & $176 \pm 27$ & $<0.001$ & $200 \pm 34$ & $200 \pm 30$ & $198 \pm 28$ & 0.730 \\
\hline HDL cholesterol (mgdl-1) & $53 \pm 13$ & $52 \pm 13$ & $51 \pm 12$ & 0.645 & $57 \pm 12$ & $57 \pm 12$ & $56 \pm 12$ & 0.281 \\
\hline LDL cholesterol (mg dl-1) & $115 \pm 29$ & $110 \pm 28$ & $105 \pm 25$ & $<0.001$ & $124 \pm 30$ & $124 \pm 27$ & $123 \pm 26$ & 0.889 \\
\hline Trigricerides (mg dl-1) & $122 \pm 92$ & $118 \pm 84$ & $102 \pm 60$ & 0.044 & $94 \pm 56$ & $94 \pm 48$ & $96 \pm 52$ & 0.866 \\
\hline Fasting glucose $\left(\mathrm{mg} \mathrm{dl}^{-1}\right)$ & $90 \pm 34$ & $89 \pm 25$ & $89 \pm 22$ & 0.847 & $84 \pm 17$ & $86 \pm 19$ & $86 \pm 15$ & 0.146 \\
\hline Serum creatinine $\left(\mathrm{mg} \mathrm{dl}^{-1}\right)$ & $1.02 \pm 0.14$ & $1.00 \pm 0.17$ & $1.03 \pm 0.17$ & 0.210 & $0.78 \pm 0.12$ & $0.78 \pm 0.12$ & $0.83 \pm 0.15$ & $<0.001$ \\
\hline $\begin{array}{l}\text { Estimated GFR }\left(\mathrm{ml} \mathrm{min}^{-1} \text { per }\right. \\
\left.1.73 \mathrm{~m}^{-2}\right)\end{array}$ & $63 \pm 11$ & $61 \pm 11$ & $57 \pm 10$ & $<0.001$ & $63 \pm 12$ & $60 \pm 11$ & $54 \pm 11$ & $<0.001$ \\
\hline Current smoking ( $n(\%))$ & $75(40)$ & $56(30)$ & $48(25)$ & 0.010 & $14(4)$ & $12(4)$ & $7(2)$ & 0.297 \\
\hline Hypertension (n (\%)) & $67(35)$ & $84(44)$ & $120(64)$ & $<0.001$ & $74(23)$ & $123(38)$ & $167(52)$ & $<0.001$ \\
\hline Diabetes $(n(\%))$ & $19(10)$ & $16(8)$ & $13(7)$ & 0.550 & $14(4)$ & $17(5)$ & $23(7)$ & 0.287 \\
\hline Metabolic syndrome $(n(\%))$ & $42(22)$ & $49(26)$ & 36 (19) & 0.288 & $37(12)$ & $59(18)$ & $73(23)$ & 0.001 \\
\hline
\end{tabular}

Abbreviations: BMI, body mass index; BNP, B-type natriuretic peptide; GFR, glomerular filtration rate; HDL, high-density lipoprotein; LDL, low-density lipoprotein.

high-risk subjects (0.755 (95\% CI 0.714-0.797) and 0.700 (95\% CI $0.658-0.741$ ) for men and women, respectively). The optimal thresholds for the identification of subjects with moderate and high risk were BNP concentrations of 12.0 and $22.0 \mathrm{pg} \mathrm{ml}^{-1}$ with sensitivities of $70 \%$ and $66 \%$ and specificities of $71 \%$ and $63 \%$ for men and women, respectively.

\section{DISCUSSION}

In this Japanese community-based population study, we demonstrated that plasma BNP levels had a modest ability to detect moderate-risk and high-risk subjects. BNP levels of $12.0 \mathrm{pg} \mathrm{ml}^{-1}$ for men and $22.0 \mathrm{pg} \mathrm{ml}^{-1}$ for women may be cutoff values for identifying moderate to severe $\mathrm{CHD}$ risk. 
a

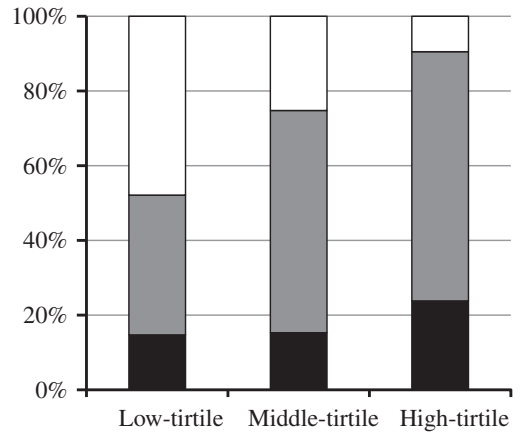

b

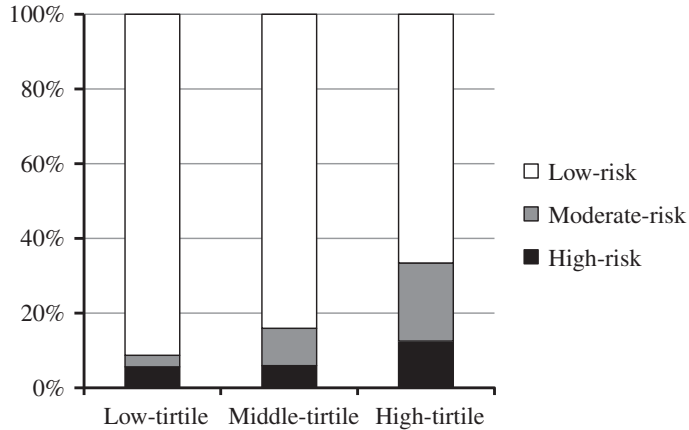

Figure 1 Distribution of Framingham risk scores according to plasma B-type natriuretic peptide (BNP) levels for men (a) and women (b).

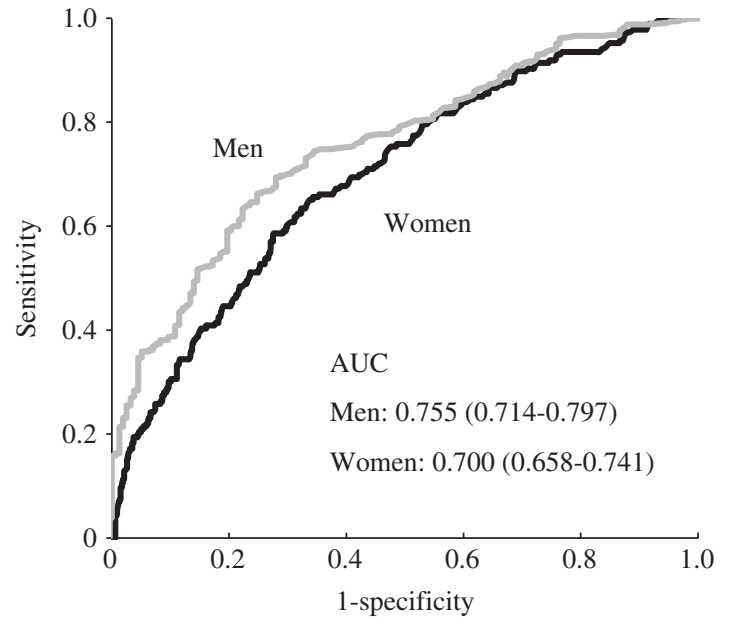

Figure 2 Receiver operating characteristic curves of plasma B-type natriuretic peptide (BNP) levels for detecting patients who are moderate risk or high risk for coronary heart disease. AUC, area under the curve.

\section{Relationship between plasma BNP levels and accumulated risk factors}

We observed a significant positive relationship between plasma BNP levels and accumulated risk factors, which was evaluated by the FRS equation, suggesting that subjects with higher plasma BNP levels may have a higher CHD risk.

The association between plasma BNP levels and individual risk factors has been described ${ }^{3,8-11,21,22}$ primarily because these risk factors are linked to LV hypertrophy and elevated LV filling pressures. The result of the present study was essentially consistent with these reports. Actually, these risk factors often coexist in a subject, and their accumulation may increase a patient's cardiovascular disease risk. However, previous studies have paid little attention to the association between plasma BNP levels and accumulated coronary risk factors. One of the studies reported that the accumulation of several metabolic risk factors was associated with low plasma BNP levels, even after adjustments for BMI. ${ }^{8}$ In contrast, our results showed that plasma BNP levels were positively associated with the accumulation of risk factors, assessed using the FRS equation.

One explanation for the differences between the results of these studies may be the differences in the components employed in each calculation, particularly age. ${ }^{13,23}$ Although advanced age, total cholesterol levels and cigarette smoking are included in the FRS equation, they are not included in the criteria for metabolic syndrome. In contrast, both obesity and elevation of diastolic blood pressure are included in the criteria for metabolic syndrome, but they are not included in the FRS equation. Among the established risk factors for CHD, advanced age is a major risk factor for CHD, independent of the other clinically available indices. ${ }^{24-26}$ As evidenced in both the present study and previous studies, advanced age is positively associated with plasma BNP levels independent of the other clinical indices. ${ }^{9,21}$ Therefore, the positive association between plasma BNP levels and accumulated risk factors, which was assessed using the FRS equation, may be attributable to advanced age. Another explanation for the differences in study results may be differences in the severity of obesity between our Japanese population and the western population. In our population, the prevalence of the normal BMI subjects, defined as a BMI of $\geqslant 25 \mathrm{~kg} \mathrm{~m}^{-2}$, was $81 \%$, in contrast to $30 \%$ in the western population. ${ }^{22}$ The usefulness of BNP levels in predicting LV filling pressures appears to decrease in severely obese subjects. ${ }^{27}$ Therefore, the positive association between plasma BNP levels and risk factors may be more distinct in our population.

In the present study, an inverse relationship between smoking and BNP levels was observed in men. Otsuka et al. ${ }^{28}$ reported that BNP levels in current smokers are higher than levels in subjects who have never smoked in a population of middle-aged men. However, differences in the populations of our study and their study should be noted. First, the mean age and the s.d. of our study (62 \pm 15 years) are higher and larger than those of the study of Otsuka et al. ${ }^{28}(44 \pm 6$ years). Second, the study population of the previous study has fewer coronary risk factors than our population. In the previous study, subjects taking medications for hypertension, diabetes, dyslipidemia and chronic renal disease were excluded. The exact mechanisms for the relationship between BNP levels and smoking status have not been elucidated, but a plausible explanation is cardiac overload caused by the excess vasoconstriction and accelerated atherosclerosis of both coronary arteries and systemic arteries caused by cigarette smoking. However, the impact of cigarette smoking on increased LV mass, which is the strongest determinant of elevated BNP levels, is smaller than that of aging, hypertension, diabetes or chronic kidney disease. Therefore, the significant relationship between smoking status and BNP levels noted in our population may be attenuated in other populations. In addition, our study subjects were arbitrary participants taken from an annual health checkup for residents of a rural town. Most of the participants appear to have sufficient motivation to undertake a healthy lifestyle, and high-risk subjects were strongly encouraged to stop smoking. Accordingly, an inverse 
relationship between smoking habits and BNP levels was observed in the present study.

\section{Clinical implications}

BNP has been widely used as a diagnostic and prognostic biomarker in heart failure. In clinical settings, plasma BNP is used as a screening tool to identify patients with heart failure or exercise intolerance. ${ }^{29,30}$ It has been reported that in general populations, plasma BNP levels can serve as a screening tool to detect LV systolic dysfunction ${ }^{1-3}$ and other heart diseases, including previous myocardial infarction and hypertensive heart disease. ${ }^{4}$ In such situations, some of the subjects have mildly elevated BNP levels even without LV dysfunction or significant valvular diseases. Our study indicated that subjects with high BNP levels but no heart failure symptoms may be moderate-risk or high-risk patients for $\mathrm{CHD}$ and, thereby, may be referred for further examination to investigate whether they have CHD or to have each risk factor for CHD treated.

\section{Study limitations}

There are some limitations to this study. First, our study population showed lower levels of obesity than those found in western populations. Because obesity may be a confounder for BNP levels, our results may be applicable to nonobese populations in western countries. Second, because of its cross-sectional nature, the present study did not indicate an association between plasma BNP levels and cardiovascular events.

The actual incidence of CHD in the Japanese population is lower than the incidence of CHD in western populations and the risk of CHD estimated by FRS. Nevertheless, it is clear that a group of subjects with higher CHD risk as determined by the FRS have a higher incidence of CHD in Chinese ${ }^{31}$ and Japanese populations. ${ }^{14}$ This suggests that the relative $\mathrm{CHD}$ risk in one race may be estimated using the FRS. Furthermore, as indicated in the Japan Atherosclerosis Society (JAS) Guidelines for Prevention of Atherosclerotic Cardiovascular Diseases, quoting the study of the National Integrated Project for Prospective Observation of Noncommunicable Disease and its Trends in the Aged (NIPPON DATA), individual risk factors are definitely associated with the incidence of cardiovascular events and absolute CHD risk should be assessed using these individual risk factors, which are also included in the formula of the FRS. Therefore, subjects with a high FRS may have a comparatively high CHD risk in a Japanese population.

Age is the strongest cofactor of the association between plasma BNP levels and FRS. Because age is included in the FRS, it is impossible to adjust for age. Although age was the variable that most strongly correlated with BNP in our study population, age is merely one component of the FRS. Although the independent association between BNP and FRS may be assessed statistically, we demonstrated a modest ability and utility of plasma BNP as a surrogate marker of the FRS as demonstrated by the area under the ROC curve as well as the sensitivity and specificity of plasma BNP. Generally, practitioners check plasma BNP levels to diagnose heart failure. When they find BNP levels above the normal range, we suggest that these practitioners should look for not only the presence of heart failure but also individual CHD risk factors, including hypertension, dyslipidemia, chronic kidney disease and age. Although age is the strongest independent predictor of $\mathrm{CHD}$, advanced age itself is not the sole risk factor for CHD.

\section{CONCLUSION}

Plasma BNP levels measured during health checkups in a Japanese general population are associated with a higher risk of CHD. Even in the normal range, plasma BNP levels have a modest ability to detect moderate-risk and high-risk subjects. Further research is necessary to verify these results and determine their relationship to future $\mathrm{CHD}$ events.

\section{CONFLICT OF INTEREST}

The authors declare no conflict of interest.

\section{ACKNOWLEDGEMENTS}

We acknowledge the assistance of the following groups and individuals: the staff of the Department of Healthcare, Arita Town, Saga, Japan; Go Ichien; Yumi Ito; and the staff of Hubit Genomix.

1 Vasan RS, Benjamin EJ, Larson MG, Leip EP, Wang TJ, Wilson PW, Levy D. Plasma natriuretic peptides for community screening for left ventricular hypertrophy and systolic dysfunction: the Framingham heart study. JAMA 2002; 288: 1252-1259.

2 McDonagh TA, Robb SD, Murdoch DR, Morton JJ, Ford I, Morrison CE, Tunstall-Pedoe H, McMurray JJ, Dargie HJ. Biochemical detection of left-ventricular systolic dysfunction. Lancet 1998; 351: 9-13.

3 Costello-Boerrigter LC, Boerrigter G, Redfield MM, Rodeheffer RJ, Urban LH, Mahoney DW, Jacobsen SJ, Heublein DM, Burnett JC Jr. Amino-terminal pro-B-type natriuretic peptide and B-type natriuretic peptide in the general community: determinants and detection of left ventricular dysfunction. J Am Coll Cardiol 2006; 47: 345-353.

4 Nakamura M, Endo H, Nasu M, Arakawa N, Segawa T, Hiramori K. Value of plasma B type natriuretic peptide measurement for heart disease screening in a Japanese population. Heart 2002; 87: 131-135.

5 Seki S, Tsurusaki T, Kasai T, Taniguchi I, Mochizuki S, Yoshimura M. Clinical significance of B-type natriuretic peptide in the assessment of untreated hypertension. Circ J 2008; 72: 770-777.

6 Wang TJ, Larson MG, Levy D, Benjamin EJ, Leip EP, Omland T, Wolf PA, Vasan RS Plasma natriuretic peptide levels and the risk of cardiovascular events and death. N Engl J Med 2004; 350: 655-663.

7 Doi Y, Ninomiya T, Hata J, Hirakawa Y, Mukai N, Ikeda F, Fukuhara M, Iwase M, Kiyohara Y. N-terminal pro-brain natriuretic peptide and risk of cardiovascular events in a Japanese community: the Hisayama study. Arterioscler Thromb Vasc Biol 2011; 31 2997-3003.

8 Wang TJ, Larson MG, Keyes MJ, Levy D, Benjamin EJ, Vasan RS. Association of plasma natriuretic peptide levels with metabolic risk factors in ambulatory individuals. Circulation 2007; 115: 1345-1353.

9 Wang TJ, Larson MG, Levy D, Leip EP, Benjamin EJ, Wilson PW, Sutherland P, Omland T, Vasan RS. Impact of age and sex on plasma natriuretic peptide levels in healthy adults. Am J Cardiol 2002; 90: 254-258.

10 Kanda H, Kita Y, Okamura T, Kadowaki T, Yoshida Y, Nakamura Y, Ueshima H. What factors are associated with high plasma B-type natriuretic peptide levels in a general Japanese population? J Hum Hypertens 2005; 19: 165-172.

11 Olsen MH, Hansen TW, Christensen MK, Gustafsson F, Rasmussen S, Wachtell K, Borch-Johnsen $\mathrm{K}$, Ibsen $\mathrm{H}$, Jørgensen T, Hildebrandt P. N-terminal pro brain natriuretic peptide is inversely related to metabolic cardiovascular risk factors and the metabolic syndrome. Hypertension 2005; 46: 660-666.

12 Grundy SM, Balady GJ, Criqui MH, Fletcher G, Greenland P, Hiratzka LF, Houston-Miller N, Kris-Etherton P, Krumholz HM, LaRosa J, Ockene IS, Pearson TA, Reed J, Washington R, Smith SC Jr. Primary prevention of coronary heart disease: guidance from Framingham: a statement for healthcare professionals from the AHA Task Force on Risk Reduction. American Heart Association. Circulation 1998; 97: 1876-1887.

13 Expert Panel on Detection, Evaluation, and Treatment of High Blood Cholesterol in Adults. Executive Summary of The Third Report of The National Cholesterol Education Program (NCEP) Expert Panel on Detection, Evaluation, And Treatment of High Blood Cholesterol In Adults (Adult Treatment Panel III). JAMA 2001; 285: 2486-2497.

14 D'Agostino RB Sr, Grundy S, Sullivan LM, Wilson P, CHD Risk Prediction Group. Validation of the Framingham coronary heart disease prediction scores: results of a multiple ethnic groups investigation. JAMA 2001; 286: 180-187.

15 Klapholz M, Maurer M, Lowe AM, Messineo F, Meisner JS, Mitchell J, Kalman J, Phillips RA, Steingart R, Brown EJ Jr, Berkowitz R, Moskowitz R, Soni A, Mancini D, Bijou R, Sehhat K, Varshneya N, Kukin M, Katz SD, Sleeper LA, Le Jemtel TH, New York Heart Failure Consortium. Hospitalization for heart failure in the presence of a normal left ventricular ejection fraction: results of the New York Heart Failure Registry. J Am Coll Cardiol 2004; 43: 1432-1438.

16 Fischer M, Baessler A, Hense HW, Hengstenberg C, Muscholl M, Holmer S, Döring A Broeckel U, Riegger G, Schunkert H. Prevalence of left ventricular diastolic dysfunction 
in the community. Results from a Doppler echocardiographic-based survey of a population sample. Eur Heart J 2003; 24: 320-328.

17 Eguchi K, Kario K, Hoshide S, Hoshide Y, Ishikawa J, Morinari M, Hashimoto T, Shimada K. Smoking is associated with silent cerebrovascular disease in a high-risk Japanese community-dwelling population. Hypertens Res 2004; 27: 747-754.

18 Eguchi K, Kario K, Hoshide S, Ishikawa J, Morinari M, Shimada K. Nocturnal hypoxia is associated with silent cerebrovascular disease in a high-risk Japanese community-dwelling population. Am J Hypertens 2005; 18: 1489-1495.

19 Examination Committee of Criteria for 'Obesity Disease' in Japan; Japan Society for the Study of Obesity. New criteria for 'obesity disease' in Japan. Circ J 2002; 66: 987-992.

20 Matsuo S, Imai E, Horio M, Yasuda Y, Tomita K, Nitta K, Yamagata K, Tomino Y, Yokoyama $\mathrm{H}$, Hishida A, Collaborators developing the Japanese equation for estimated GFR. Revised equations for estimated GFR from serum creatinine in Japan. Am J Kidney Dis 2009; 53: 982-992.

21 Redfield MM, Rodeheffer RJ, Jacobsen SJ, Mahoney DW, Bailey KR, Burnett JC Jr. Plasma brain natriuretic peptide concentration: impact of age and gender. J Am Coll Cardiol 2002; 40: 976-982.

22 Wang TJ, Larson MG, Levy D, Benjamin EJ, Leip EP, Wilson PW, Vasan RS. Impact of obesity on plasma natriuretic peptide levels. Circulation 2004; 109: 594-600.

23 Grundy SM, Cleeman JI, Daniels SR, Donato KA, Eckel RH, Franklin BA, Gordon DJ, Krauss RM, Savage PJ, Smith SC Jr, Spertus JA, Costa F, American Heart Association; National Heart, Lung, and Blood Institute. Diagnosis and management of the metabolic syndrome: an American Heart Association/National Heart, Lung, and Blood Institute Scientific Statement. Circulation 2005; 112: 2735-2752.

24 Gordon T, Castelli WP, Hjortland MC, Kannel WB, Dawber TR. Predicting coronary heart disease in middle-aged and older persons: the Framingham Study. JAMA 1977; 238: 497-499.
25 Schildkraut JM, Myers RH, Cupples LA, Kiely DK, Kannel WB. Coronary risk associated with age and sex of parental heart disease in the Framingham Study. Am J Cardiol 1989; 64: 555-559.

26 Dannenberg AL, Levy D, Garrison RJ. Impact of age on echocardiographic left ventricular mass in a healthy population (the Framingham Study). Am J Cardiol 1989; 64: 1066-1068.

27 Dokainish H, Gonzalez R, Hartley WB, Caldera A, Koshy S, Sengupta R, Lakkis NM. Usefulness of B-type natriuretic peptide levels to predict left ventricular filling pressures in patients with body mass index $>35,31$ to 35 , and $<$ or $=30 \mathrm{~kg} / \mathrm{m}^{2}$. Am J Cardiol 2007; 100: 1166-1171.

28 Otsuka T, Kawada T, Seino Y, Ibuki C, Katsumata M, Kodani E. Relation of smoking status to serum levels of $\mathrm{N}$-terminal pro-brain natriuretic peptide in middle-aged men without overt cardiovascular disease. Am J Cardiol 2010; 106: 1456-1460.

29 Maisel AS, Krishnaswamy P, Nowak RM, McCord J, Hollander JE, Duc P, Omland T, Storrow AB, Abraham WT, Wu AH, Clopton P, Steg PG, Westheim A, Knudsen CW, Perez A, Kazanegra R, Herrmann HC, McCullough PA. Breathing Not Properly Multinational Study Investigators. Rapid measurement of B-type natriuretic peptide in the emergency diagnosis of heart failure. N Engl J Med 2002; 347: 161-167.

30 Mueller C, Maeder MT, Christ A, Reichlin T, Staub D, Noveanu M, Breidthardt T, Potocki M, Brutsche MH. B-type natriuretic peptides for the evaluation of exercise intolerance. Am J Med 2009; 122: 265-272.

31 Liu J, Hong Y, D'Agostino RB Sr, Wu Z, Wang W, Sun J, Wilson PW, Kannel WB, Zhao D. Predictive value for the Chinese population of the Framingham CHD risk assessment tool compared with the Chinese Multi-Provincial Cohort Study. JAMA 2004; 291: 2591-2599. 